\title{
Natural Knowledge: An Analysis of Plantinga's Reformed Epistemology in Light of Contemporary Cognitive Science of Religion
}

\author{
Dominik Whittaker \\ Palacký University Olomouc
}

\begin{abstract}
The foundation of Alvin Plantinga's reformed epistemology is the idea that beliefs which are naturally, non-inferentially and immediately produced by a cognitive faculty are properly basic. A properly basic belief is one that ought to be held as true, even if there is no evidence or argument to confirm it. Such a belief should only be rejected once sufficient evidence or a sound argument can be found to disprove it. Plantinga's most important claim is that belief in God is one such belief, produced by a cognitive faculty which he calls the sensus divinitatis. In this paper I will first examine three major accounts of the origin of religious beliefs from the cognitive science of religion, not only to show that such beliefs exist but also to see if any one of these accounts could be considered a scientific account of the sensus divinitatis. I will then examine reformed epistemology itself in order to find out whether or not Plantinga is correct in saying that these beliefs ought to be held as true until disproven and to see if Plantinga's properly basic beliefs can be considered a form of knowledge.
\end{abstract}

\section{Keywords}

properly basic beliefs; reformed epistemology; cognitive science of religion; comparative study; faith; contemporary epistemology; Alvin Plantinga; Justin L. Barret; HADD-ToM-eToM; Pascal Boyer

\section{Contact address}

Dominik Whittaker (M.A.), Department of Philosophy, Palacky University Olomouc, Czech Republic e-mail: dominik.whittaker01@upol.cz

The defining characteristic of Plantinga's reformed epistemology is the belief in the reliability of natural non-inferential beliefs that are produced by a cognitive faculty. The most impactful claim made by reformed epistemologists is the claim that belief in God is properly basic and as such it is a belief that should be held until good enough reasons for discarding 
it are found. In order for such an epistemology to be adopted, two propositions must be found to be true. The first being that properly basic beliefs, as defined by Plantinga, exist, i.e. that certain beliefs that people hold are naturally and immediately produced by a cognitive faculty without the help of an inference. The second is that Plantinga is correct in saying that these beliefs should be held to be true until some empirical evidence or rational argument is found to discredit them. ${ }^{1}$

In the first part of this paper, I will examine contemporary research in the cognitive science of religion in an attempt to find out if there is scientific evidence that some beliefs, specifically religious beliefs, are naturally, immediately and non-inferentially produced, either by a cognitive faculty or by a number of cognitive faculties working in tandem, in order to determine if we have sufficient reason to believe that the first of the aforementioned propositions is true.

In the second part of the paper, I will attempt to answer two questions, the first being whether or not Plantinga is correct in his claim that basic beliefs should be held to be true until they are proven to be false, since answering this question will show whether the second of the aforementioned propositions is true or false. The second question that this part of the paper will deal with is whether basic beliefs should be considered to be a form of knowledge.

\section{Part one: Are some beliefs natural? Reformed epistemology and cognitive science}

Before starting on the comparison of the claims of reformed epistemology and the findings of cognitive science, a more detailed explanation of reformed epistemology and basic beliefs is in order. According to Plantinga, the defining characteristic of a basic belief is the fact that it is not inferred from other beliefs, ${ }^{2}$ For example, the belief that my shoulder hurts is a basic belief since it is based on the immediate experience of pain and I do not need to assess the implications of any other beliefs I might hold and make an inference based on that. In other words, basic beliefs are "non-inferential". An example of a non-basic belief would be the belief that the city of Manchester is in the north of England, which is based on my belief that maps, the testimonies of others and other relevant sources are reliable. Basic beliefs serve as the basis or foundation for other beliefs, which is what makes them "basic". Returning to the previous example, my belief that my shoulder hurts can be the basis for my belief that I should take a rest from exercise or that I should see a doctor. The most important thing is not that some beliefs are basic, but that some beliefs are properly basic. This means they are basic beliefs, that it is rational to believe them in the absence of evidence or arguments, and the most important questions regarding such beliefs are

\footnotetext{
${ }^{1}$ The publication of the paper was enabled by the support of MŠMT ČR (Ministry of Education, Youth, and Sports of the Czech R-epublic) given to Palacký University Olomouc (IGA_FF_2019_018).

${ }^{2}$ Alvin Plantinga, "Is Belief in God Properly Basic?” Nous (1981): 41-51, 41.
} 
what criteria a basic belief must meet in order to be considered properly basic and what beliefs meet these criteria.

One major innovation made by reformed epistemology is the altering of the criteria for a properly basic belief from the criteria put forward by classical foundationalism in a way that expands the scope of beliefs that should be considered properly basic. In classical foundationalism, the criteria for a properly basic belief are laid out as follows: "First, a proposition is properly basic if it is self-evident, incorrigible, or evident to the senses, and second, a proposition is properly basic only if it meets these conditions." 3 Reformed epistemology expands these criteria to include beliefs such as the belief in other minds, the belief in the reliability of our memories and the belief in God. The first two of these beliefs are neither incorrigible, nor self-evident, nor evident to the senses, but virtually everyone would consider them to be properly basic. A set of criteria that these beliefs seem to meet is that they are immediately produced by a cognitive faculty, that is working correctly and is in an environment that is appropriate for it. For the sake of brevity I will refer to such beliefs as natural beliefs for the rest of this paper. Even very young children will believe that people around them have minds, that what they remember is what happened and each of these beliefs is produced by a correctly working cognitive faculty. Plantinga argues that belief in God also meets these criteria, postulating a cognitive faculty, which he calls the "sensus divinitatis", ${ }_{4}^{4}$ a faculty that leads people towards belief in God when they are confronted with certain experiences for example the experience of guilt or the experience of great beauty. The sensus divinitatis also produces a sense of God's presence when faced with other experiences, such as the experience of prayer or a church service.

In the following part of this paper, I will examine what the cognitive science of religion has to say about whether or not belief in God is natural. The purpose of this is to determine if certain objections to reformed epistemology might be sound, specifically objections which argue that no belief is natural. Such objections may be based on the idea that there is no such thing as human nature, an idea put forward by Jean Paul Sartre among others. They might also be based on the Lockean notion that the human mind is a blank slate. Another reason to examine what Cognitive science has to say about whether or not belief in God is natural is to determine the truth or falsehood of Plantinga's claim that a sensus divinitatis exists and that belief in God is natural, since very few people would deny the naturalness of believing one's own memory or believing in other minds. The naturalness of belief in God, however, is still very much in dispute, and if belief in God is in fact natural then if reformed epistemology is accepted as an epistemology, the proposition that God exists must be assented to.

The cognitive science of religion has produced three major accounts of how religious beliefs might be naturally produced by the human mind. These are the attribution account, the dispositional account and the preparedness account. The attribution account sees

\footnotetext{
${ }^{3}$ Dewey J. Hoitenga, Faith and Reason from Plato to Plantinga: An Introduction to Reformed Epistemology, (Albany, NY: SUNY Press, 1991), 148.

${ }^{4}$ Alvin Plantinga, Warranted christian belief(Oxford: Oxford University Press, 2000).
} 
religious beliefs as the by-product of two cognitive faculties working together, specifically the hypersensitive agency detection device or HADD and the theory of mind or ToM. Advocates of the attribution account claim that the human cognitive faculty responsible for determining whether or not events, such as a sudden bump in the night, and objects are the products of intentional agents evolved to be hypersensitive, meaning that it is far more likely to produce a false positive than it is to produce a false negative. ${ }^{5}$ The reason for this is that for our early ancestors the false attribution of an event to intentional agents would have no severe consequences, but failing to recognise agency where it was present, could be fatal, since it could mean failure to spot the presence of a predator or an enemy. This means that those with more sensitive agency detection devices were more likely to survive and pass on their genes. When the HADD attributes agency to an event or object a second cognitive faculty, the theory of mind or ToM begins attributing thoughts, feelings, beliefs and intentions to the agent that is supposedly responsible for it. In most cases, events and objects would be attributed to human or animal agents, but sometimes events or objects that could not be the product of humans or animals would be designated as the product of an intentional agent by the HADD. This would lead to the invention of a different sort of agent, such as a god or a spirit, which could be responsible for said object or event. Once the HADD has attributed agency, the ToM begins to attribute various intentional states of consciousness to this new sort of agent based on the nature of the object or event. Kelly James Clarke and Justin L. Barrett explain this process as follows: "Upon the detection of agency the Theory of Mind (ToM) system begins operating and attributes beliefs, desires, purposes, and so forth, to the postulated agent. A full-blown god concept may be fleshed out by HADD and ToM working together, automatically and non-reflectively... what specific properties might these gods be prone to have? Much like humans, gods will have percepts, thoughts, beliefs, desires, goals, motivations, and emotions. Likely, they will have language, communication, and social relations. All of these basic attributes come automatically from ToM. Though Guthrie emphasizes the attribution of human properties (hence, he regards his as a new anthropomorphism theory of religion), he admits that the cognitive faculties at play invite more flexible input conditions than distinctly human agency." 6 Though the original version of the attribution account advocated by Steward Guthrie, among others, included only the two aforementioned faculties, more recently Jesse Berring ${ }^{7}$ has proposed a version of the attribution account, which is expanded by one additional faculty, which Berring calls eTom or "the existential theory of mind". This faculty is responsible for attributing events such as coincidences and great fortune or misfortune to a mind or minds. In other words, the eTom is the common human tendency to ask questions such as "why did this have to happen to me?" or "what did I do to deserve such

5 See Stewart Elliott Guthrie, Faces in the clouds: A new theory of religion (Oxford: Oxford University Press, 1995) for a detailed explanation of how the HADD functions and of the attribution account in general.

${ }^{6}$ Kelly James Clark and Justin L. Barrett, "Reformed epistemology and the cognitive science of religion," Faith and Philosophy 27, no. 2 (2010): 174-189, 178.

${ }^{7}$ Jesse M. Bering, "The existential theory of mind," Review of General Psychology 6, no. 1 (2002): 3-24. 
luck?" and to answer these questions by postulating some sort of mind that is responsible for such events, attributing misfortune to divine punishment, for example. The introduction of this faculty expands the range of experiences that might be attributed to another agent by the human mind thereby potentially leading to beliefs in supernatural agents and eventually to religious belief and practice. The attribution account, therefore, claims that religious beliefs are naturally and non-inferentially produced by a set of cognitive faculties, as well as claiming that belief in gods comes as a reaction to certain experiences, which makes it, in some ways, remarkably similar to Alvin Plantinga's reformed epistemology. This account however, differs from Plantinga's reformed epistemology in some important ways, which will be discussed later in this paper.

The second account has been dubbed the "dispositional account" by Clarke and Barrett. ${ }^{8}$ This is because on this account several cognitive faculties work together to produce a natural disposition towards religious belief. This account is championed by Pascal Boyer who identifies a large number of highly specialised cognitive faculties, including the faculty responsible for identifying particular sounds as language, the natural tendency to overstimulate the visual cortex and the faculty meant to identify contaminants and toxins, ${ }^{9}$ which work together to produce belief in God or in gods. Boyer models the spread of certain ideas as the spread of a disease in order to explain why religious beliefs arise regardless of geography or cultural context. Clarke and Barrett point out that "Analogously to studying the spread of disease in a population, to understand the spread of ideas in a population, we must understand the properties of the host organism in relation to the potentially 'infecting' ideas and how they might spread from person to person". ${ }^{10}$ Boyer lists four properties of ideas that are likely to spread successfully "(1) are easily and readily represented by human cognitive equipment, (2) are attention-demanding regardless of cultural conditions, (3) have rich 'inferential potential' such that they readily generate inferences, explanations, and predictions relevant to many domains of human concern, and (4) motivate actions that reinforce belief" ${ }^{11}$ He argues that the concepts of gods and supernatural agents, that are most common in religious systems, all have four of these properties.

The third account is called the preparedness account and is the result of experimental evidence acquired by developmental psychologists studying religious acquisition in children. The central claim of the preparedness account is that, from an early age, children develop a set of cognitive biases towards seeing the world as a result of design, thereby "preparing" them to accept religious beliefs. Some examples of this were found by developmental psychologist Deborah Kelemen in her research where she found that children tend to see natural objects such as trees as being designed for a purpose and that children come to these conclusions on their own without being taught. Kelemen observed that "when asked to

\footnotetext{
${ }^{8}$ Clark and Barrett, "Reformed epistemology," 179.

9 See Pascal Boyer, Religion explained: The Evolutionary Origins of Religious Thought, (New York: Basic Books, 2008).

${ }^{10}$ Clark and Barrett, "Reformed epistemology", 180.

${ }^{11}$ Ibid.
} 
identify unanswerable questions, American 4- and 5-year-olds differ from adults by finding the question "what's this for?" appropriate not only to artifacts and body parts, but also to whole living things like lions ("to go in the zoo") and non-living natural kinds like clouds ("for raining")". ${ }^{2}$ She refers to this tendency as "promiscuous teleology" ${ }^{13}$ and according to the results of other experiments, ${ }^{14}$ even very young children know that teleology is the domain of minds. Not only are children prepared by their cognitive equipment to accept that there is purpose behind natural objects and that this purpose was given to them by a mind that created them, but they are also prepared to accept the idea that this mind has superhuman qualities such as superhuman powers of perception and knowledge and immortality, ${ }^{15}$ all qualities, which are commonly attributed to God or gods. There is even some evidence that children are prepared to accept the immortality of human minds ${ }^{16}$ in the same way that they are prepared to accept belief in God or gods, meaning that children may be prepared to embrace belief in the afterlife as well as the existence of God or gods.

Now that these three major accounts are understood, we should examine whether, on any one of these three accounts, religious belief should be considered properly basic by the criteria set down by reformed epistemology. The attribution account shows some important similarities to Plantinga's reformed epistemology in that it presents a sensus divinitatis that creates belief in supernatural agents in response to particular experiences. Berring's addition of the "existential theory of mind" to the attribution account brings it even closer to reformed epistemology since some of the experiences that Berring identifies as leading to god beliefs (guilt, great fortune and great misfortune) are identical to the experiences that Plantinga presents when he mentions "guilt, gratitude [and] danger" 17 as

${ }^{12}$ Deborah Kelemen, "Are children intuitive theists"? Reasoning about purpose and design in nature," Psychological science 15, no. 5 (2004): 295-301, 295.

${ }^{13}$ Ibid.

${ }^{14}$ See George E. Newman, Valerie Kuhlmeier, Frank C. Keil, and Karen Wynn, 12-month-olds know that agents defy entropy: Exploring the relationship between order and intentionality, Poster presented at the Biennial meeting of the Society for Research on Child Development, Atlanta, GA, 2005.

${ }^{15}$ See Justin L. Barrett and Rebekah A. Richert, “Anthropomorphism or preparedness? Exploring children's God concepts," Review of Religious Research (2003): 300-312 for a detailed run down of studies conducted on this topic before 2003. They include the so-called "cracker box experiment" (Henry M. Wellman, David Cross, and Julanne Watson, "Meta-analysis of theory-of-mind development: The truth about false belief," Child development 72, no. 3 (2001): 655-684) which serves as the basis for a new version (Justin L. Barrett, Rebekah A. Richert, and Amanda Driesenga, "God's beliefs versus mother's: The development of nonhuman agent concepts," Child Development 72, no. 1 (2001): 50-65, Experiments 1 and 2) which shows the preparedness of children to accept the idea of a God with superhuman knowledge as well as providing evidence against the anthropomorphism hypothesis by showing that children's concept of God has non-human properties. More evidence to this end is found in Justin L. Barrett, Rebekah A. Richert, and Amanda Driesenga. "God's beliefs versus mother's: The development of nonhuman agent concepts." Child Development 72, no. 1 (2001): 50-65, Experiment 3.

${ }^{16}$ See Paul Bloom, Descartes' baby: How the science of child development explains what makes us human, (New York: Basic Books 2005). See also Jesse M. Bering and David F. Bjorklund, "The natural emergence of reasoning about the afterlife as a developmental regularity," Developmental psychology 40, no. 2 (2004): 217-233. ${ }_{17}$ Plantinga, "Is belief in God properly basic?", 46. 
experiences, which might provide grounds for belief in God. In the way that HADD-ToMeToM produces religious beliefs, it appears to be almost identical to the God faculty put forwards by Plantinga. The only difference when it comes to function is greater specificity in terms of how this faculty works and why it works the way that it does (to detect potentially helpful or dangerous agents, and to reason about their motives). The differences between the attribution account and the God faculty of reformed epistemology become apparent, however, once we start to consider the kinds of beliefs that are produced on either account, and why they are produced. What Plantinga describes is a faculty that produces belief in God, the omnipotent, omniscient and morally perfect being of Christian scripture. ${ }^{18}$ The three faculties of the attribution account are more likely to produce a vision of a world that is filled with minor supernatural beings such as fairies or yokai, since the HADD would be triggered by all sorts of events that are very different from each other which would likely lead to the postulation of agents that are as different from each other as the events that they are supposedly responsible for. Although beliefs that are accepted as a result of HADD-ToM-eTom, certainly match the above described criteria for a properly basic belief, i.e. that they are natural beliefs, the kinds of beliefs that it is likely to produce present a problem for anyone wanting to argue that beliefs generated by the cooperation of these faculties should be accepted as properly basic. Since beliefs generated by these faculties are potentially so diverse it would most likely lead to each individual believing in a number of supernatural agents that fit with the experiences that they had throughout their life that triggered HADD-ToM-eToM. However, a society might synthesize all of these beliefs into a single system (a religion) that does not teach contradictory ideas. Individual societies will develop their own religions that will contradict each other in one way or another. The problem lies in the fact that accepting beliefs that are the product of HADD-ToM-eToM, solely on the basis that they are the natural products of these faculties, would mean that all of these self-contradictory beliefs would have to be accepted as properly basic, and should all be accepted as true until there is a sufficient reason to reject them. If reformed epistemology were to be accepted, HADD-ToM-eToM was identified as the god faculty and its products were accepted as properly basic then it could be said that this epistemological theory proves too much in the sense that it gives grounds for belief to a great multitude of contradictory ideas. If the claim is made that each person should hold any belief produced by HADD-ToM-eToM as properly basic it would lead to a situation where any belief regarding a supernatural agent would be seen as justified and since many of these beliefs would contradict each other, adopting reformed epistemology would tell us nothing about the truth or falsehood of any particular claim about the properties, intentions or number of supernatural agents. One claim is just as valid as another, if there is no evidence against either one. Another major problem of equating HADD-ToM-eToM with the sensus divinitatis is a practical one, stemming from the fact that religious beliefs are inextricably linked with ethics. If it is claimed that everyone

${ }^{18}$ See Ibid. In particular p. 46 where Plantinga talks about a "strong sense that God is speaking" being produced when one reads the Bible, making it clear that he is talking about the Christian God specifically. 
should consider their religious belief to be properly basic then it follows that they should also hold ethical values that are implicit in those beliefs. Claiming that each individual is not only entirely rational in holding such beliefs but that they ought to hold them would lead to an untenable form of moral relativism that would make debate in the sphere of ethics virtually impossible. In order to argue against one of the many moral systems that is underpinned by one of the many religious systems produced by HADD-ToM-eToM, one would have to present sufficient evidence against the religious system and very often such evidence cannot be found. The result of this would be a multitude of moral systems and no reason to favour one moral system over another and therefore no possibility of arguing for a single set of values that all people should adhere to. This means that the idea that the attribution account is a scientific account of the sensus divinitatis must be dismissed or an explanation must be provided for how HADD-ToM-eToM could produce beliefs that should be considered properly basic while avoiding the problems described above.

One such explanation might be the idea that individual beliefs, which these faculties produce, should not be considered natural and therefore should not be considered properly basic, since a natural belief is a belief that is innate to a human nature that all human beings share and is therefore naturally produced in everyone. The diverse beliefs produced by these faculties do not fit this description of natural beliefs but there are beliefs that are implicit in any belief in a supernatural agent and these beliefs would be natural since HADD-TOM-eToM is present in each person and directs them towards belief in supernatural agents. These beliefs include the idea that supernatural agents exist, that minds can exist without bodies and that the laws of nature are not inviolable. It is these beliefs, which are universally produced by HADD-TOM-eToM, that are to be considered to be properly basic and not specific beliefs that only exist in particular individuals and societies. Even though this particular account of the God faculty describes a faculty that does fairly little to produce Christian faith or even monotheism, the most common defenders of reformed epistemology, reformed Christians, may see this fact as a consequence of the impact that the fall of Adam and Eve had on all of human nature, including the god faculty. Where once human beings had a perfect awareness of where and when God was working in nature, they now have a vague sense that something is working in nature and that it has some of the qualities that God has (e.g. agency, supernatural powers and an interest in the affairs of humans). However, it is possible that a reformed Christian interpretation of this account could show how HADD-TOM-eToM may ultimately lead to a belief in something like the Christian God. The aspect of the attribution account that is most likely to help in producing monotheistic or Christian beliefs is undoubtedly Bering's eToM since it hints at a being that at the very least has super human knowledge, interest in the lives of humans and, most importantly, dictates the fates of human beings. With the way that Berring described the eToM, as a faculty that attributes great fortune and misfortune to a powerful agent that is powerful enough to have a great deal of control over the lives of humans and is knowledgeable enough to always be aware of what is happening in someone's life, it is likely that such beliefs would spread in a society as people began to share the experiences that lead them to the belief that there is a supernatural agent that 
acts in their lives, since most of the people that they would share their belief with would have had similar experiences and would be naturally inclined to accept a belief in such an agent. Since the eToM produces belief in an agent that has a single set of properties, it is not difficult for a society to come to the conclusion that the agent that they believe acts in the lives of each of its members is a single person, which means that a belief in an agent that knows the lives of every person in the society, and is powerful enough to interfere in them in a major way, will form. This idea of an agent that knows the life of every person and seems to have perfect control over each person's fortune or misfortune starts to look very much like the omnipotent and omniscient God of the Abrahamic faiths, although it is missing one key component, moral perfection. There is nothing in the way that the eToM works that would make someone believe that the agent acting in their lives is moral, let alone morally perfect. Someone whose entire life had been characterised by horrible misfortune would be particularly unlikely to believe that the being dictating their life was morally perfect. We can see that while some beliefs that are implicit in beliefs produced by HADD-ToM-eToM could be considered properly basic beliefs, as defined by reformed epistemology, these beliefs are too vague to support any one religious system or even any one kind of religious system, and while the eToM might help in forming monotheistic beliefs in people, it is not enough to produce belief in the Abrahamic God on its own, meaning that advocates of reformed epistemology who equate the God faculty with HADD-ToMeToM could not argue that belief in the God of the Bible is properly basic since on this account it is not naturally produced by these faculties.

Unlike the attribution account, the dispositional account differs from Plantinga's idea of the God faculty in that it does not describe faculties that form beliefs as a response to certain experiences or certain states of mind. However, the dispositional account puts a great deal of emphasis on the innateness of god beliefs, since god beliefs are created as a by-product of a great many cognitive faculties in a normally functioning human mind in a normal environment without need for any assistance or stimulation from outside of the mind, meaning that the god beliefs that the human mind produces on the dispositional account perfectly match the criteria for a properly basic belief laid down by reformed epistemology since a mind does not have to exist in any particular circumstances in order to produce these beliefs meaning that these beliefs are purely a natural product of the human mind that is accepted without the need for an inference, similar to the belief that the external world or other minds exist.

The preparedness account is unique among the three accounts in the specificity of the sorts of god beliefs that it produces and in the fact that the naturalness of beliefs, that the god faculty produces on the preparedness account, can be backed up by the fact that they have been observed in children without the children having been taught them and in the fact that these beliefs, that children seem to have regarding design in nature, are produced immediately, meaning that they do not need time to develop either through frequent experiences that trigger the $\mathrm{HADD}$ or the $\mathrm{eToM}$, as in the attribution account, or through the workings of a host of cognitive faculties that may produce a religious belief or may simply 
make one more receptive to a religious belief preached by someone else. This is evident from the fact that none of the studies done on this subject found a gradual development of these beliefs as children age, they simply seem to be there at a very early age. The children seem to express these beliefs as though they were the most obvious thing in the world and "are resistant to alternative explanations (such as evolution by natural selection) until fairly late in childhood". ${ }^{19}$ This is perhaps the closest connection to the two properly basic beliefs that Plantinga brings up for comparison with belief in God, i.e. the belief in the reliability of memory and in other minds, since what these two beliefs have in common with children's belief in teleology in nature, on the preparedness account, is that they appear immediately at a very young age, do not need to be taught and are treated as obvious facts by those who believe them. All of this means that these beliefs that children naturally assent to clearly do meet the criteria for properly basic beliefs laid down by reformed epistemology but the preparedness account does seem to present a problem for reformed epistemology which is the fact that the preparedness account appears to present a god faculty that is only present in children. On the preparedness account, religious beliefs arise in children as a result of beliefs, like the belief in teleology in nature, that are natural to children, but once these children mature religious beliefs will endure as a result of the confirmation bias, the human tendency to seek out evidence that confirms what one already believes and to ignore any evidence that contradicts it. This would mean that identifying the sensus divinitatis with the cognitive biases, described by the preparedness account, would result in a theory of the god faculty that creates religious beliefs, naturally and immediately, in children but not in adults, and if a belief is not natural to a certain group of people then those people would have no reason to consider that to be belief properly basic. The only way to make the preparedness account fit with reformed epistemology would be to present data that shows that cognitive biases, similar to those that developmental psychologists have found in children, continue to exist in adults. Fortunately for reformed epistemology, such data does exist. In his response to Geertz and Markússon, ${ }^{20}$ Jesse Bering cites a study, ${ }^{21}$ which he conducted with B.T Heywood, where "self-described British and American atheists were asked quasi-structured interview questions about their own major life events". ${ }^{22}$ Bering describes the results of this study as follows: "Many of these individuals' answers revealed an implicit attribution of teleo-functional fatalistic purpose to these turning points in their lives". ${ }^{23}$ He gives an example of one woman he interviewed who claimed that one of

${ }^{19}$ Clark and Barrett, "Reformed epistemology", 183.

${ }^{20}$ Jesse Bering, "Atheism is only skin deep: Geertz and Markússon rely mistakenly on sociodemographic data as meaningful indicators of underlying cognition," Religion 40, no. 3 (2010): 166-168. Bering's response to Armin W. Geertz and Guðmundur Ingi Markússon, "Religion is natural, atheism is not: On why everybody is both right and wrong," Religion 40, no. 3 (2010): 152-165.

${ }^{21}$ Bethany Heywood and Jesse Bering, Do atheists reason implicitly in theistic terms? Evidence of teleo-functional biases in the autobiographical narratives of nonbelievers, Unpublished manuscript, Faculty of Theology and Religion, University of Oxford, Oxford, UK, 2010.

22 Bering, "Atheism is only skin deep", 167.

${ }^{23}$ Ibid. 
the most important events in her life was losing her scholarship due to failing one of her courses. When asked why she thought this happened she said, "so that I could see that if I failed a course, my life wouldn't actually end" ${ }^{24}$ Rather than attributing her failure to insufficient effort on her part or to any number of non-teleological explanations, she chose, despite her unbelief, to describe her misfortune as happening for a purpose, specifically for the purpose of teaching her a lesson. Such an explanation does not make sense if there is not an agent behind the event that has the intention of teaching a lesson, the power to dictate people's lives and enough knowledge of people's lives and futures to know when and how to intervene. The fact that someone who is consciously an atheist intuitively produced a belief that requires the existence of a being very much like God points to the existence of a cognitive bias in adults very much like the promiscuous teleology that Kelemen observed in children, only it seems to be more complex and less promiscuous than what is observed in children instead of automatically attributing purpose to animals and natural objects. Purpose is attributed to events and as far as Bering's study could find, only to the most major events. If the results of this study, and Bering's interpretation of them, are accepted then it does seem that the cognitive biases that develop in children continue to exist in adults in some form. This single study cannot show conclusively that this natural tendency towards implicitly theistic beliefs exists in all people across all cultures, although it certainly does provide some evidence for the naturalness of theistic beliefs. It is important to note that the research supporting intuitive theism in children suffers from a similar problem, which is that it has been conducted exclusively on children growing up in historically Christian countries where, one might argue, they might be culturally rather than naturally predisposed to the idea that the natural world is designed with a purpose. In both cases, more research is needed before the naturalness of theism can be said to be a scientific fact, in particular research done with subjects from different cultures. This does not change, however, the fact that there is a large amount of experimental data that supports the idea that some form of theism is natural to humans from early childhood, supporting the preparedness account by extension and providing reformed epistemology with a scientific account of a God faculty that is highly specific, in that it produces belief in an agent that is similar in many ways to the Abrahamic God.

\section{Part 2: Should Plantinga's basic beliefs be held to be true?}

Having shown that there is evidence to support the fact that some religious beliefs are natural, Plantinga's claim that such beliefs are properly basic should be examined in order to find out whether or not he is correct. Any epistemological system besides absolute scepticism accepts that some beliefs are properly basic. These beliefs include the belief in the reliability of reason and experience; the belief that the future will resemble the past and and other first principles that make knowledge possible. What differs from one system to

${ }^{24}$ Ibid. 
the next are the criteria for what is a properly basic belief. Plantinga's justification of his own criteria for what should be considered a properly basic belief begins with a critique of the criteria laid down by classical foundationalism, i.e. "First, a proposition is properly basic if it is self-evident, incorrigible, or evident to the senses, and second, a proposition is properly basic only if it meets these conditions". ${ }^{25}$ Plantinga accepts the first of these two criteria but contests the second claiming that there are some beliefs that are universally accepted as properly basic namely the belief that our memories are reliable and the belief that other minds exist. ${ }^{26}$ Neither of these beliefs fit these criteria, none of our senses can access the mind of another person nor can they access the past to verify our memories. The belief in other minds could be corrected, in theory, if solipsism were shown to be true and our memories often are corrected by other testimonies of the same event. Neither of these beliefs is self-evident, there is nothing in the concept that memory is reliable or in the concept of other minds existing that provides grounds to believe that this concept is an accurate description of reality. Despite all of this, virtually everyone would consider these to be properly basic beliefs. Plantinga also argues that this criterion for properly basic beliefs is incoherent, since classical foundationalists believe in this criterion and it is impossible to demonstrate the validity of such a principle with evidence, meaning that in order for this principle to be believed it would have to be properly basic and it clearly does not meet its own criterion for a properly basic belief. This makes it a self-contradictory belief since it is necessary to renounce it in order to believe it and it is therefore incoherent. The incoherence of this criterion whose role was to establish the boundary between what is and what is not a properly basic belief means it seems that a new criterion is needed to establish a new boundary, one that allows for a greater number of beliefs to be considered properly basic.

Plantinga goes further than simply inventing a new criterion for basic belief to replace the criterion of classical foundationalism, ${ }^{27}$ claiming that it can be rational for one to hold a belief to be properly basic even if one does not have a clearly defined criterion for what beliefs are properly basic. ${ }^{28}$ This immediately presents a problem since without a criterion it seems that any answer to the question of whether or not a particular belief is properly basic is completely arbitrary and any belief could be called properly basic even those that are clearly irrational. Plantinga anticipates this objection and claims that what distinguishes legitimate properly basic beliefs from irrational beliefs is that a properly basic belief is not groundless. It is important to point out the difference between evidence and Plantinga's definition of grounds, ${ }^{29}$ since a belief based on evidence is not basic. Evidence is a body of facts that must be believed in order to justify another belief, meaning that any belief that is based on evidence cannot be basic, since it is based on another belief. A belief that has grounds can be a basic belief, however, since grounds are not beliefs but "conditions

\footnotetext{
${ }^{25}$ Hoitenga, Faith and reason, 148.

${ }^{26}$ Plantinga, "Is belief in God properly basic?", 44-45.

${ }^{27}$ Hoitenga, Faith and reason, 185-186.

${ }^{28}$ Plantinga, "Is belief in God properly basic?", 48-49.

${ }^{29}$ Ibid., 46.
} 
or circumstances ${ }^{130}$ which act on some cognitive faculty in a way that causes them to immediately produce basic beliefs. To help explain what he means by grounds and how these grounds can justify beliefs, Plantinga provides an example: "Upon having experience of a certain sort, I believe that I am perceiving a tree. In the typical case, I do not hold this belief on the basis of other beliefs; it is nonetheless not groundless. My having that characteristic sort of experience... plays a crucial role in the formation of that belief. It also plays a crucial role in its justification." 31 This example shows that a belief like the one that Plantinga describes, one that is produced immediately by some cognitive faculty as a response to an experience, without any need for recourse to other beliefs, finds its grounds in the experience itself rather than a body of evidence, and "that a belief is properly basic only in certain conditions [and that] these conditions are ... the ground of its justification and, by extension, the ground of the belief itself". ${ }^{32}$ While it is impossible for anyone to deny that such immediately produced beliefs should be believed without denying the reliability of his own memory and perceptions, there are some important things to point out about what has been said about the grounds for a properly basic belief so far. Firstly, such beliefs may not be founded on evidence, but it is possible to refute them with evidence. For example, if a man, who knows that he has a tendency to hallucinate trees, is walking through a barren desert and sees a single tree growing in the sand, his knowledge of his odd condition and his knowledge that he is in a place where trees do not grow serve as evidence against the immediately produced belief that he is perceiving a real tree. Secondly, if this is all there is to the grounding of properly basic beliefs then each person will have their own set of properly basic beliefs that is defined by their own subjective experiences, one person's properly basic belief may even contradict those of other people. This does not serve as evidence against the idea that these beliefs are properly basic, if multiple people have experienced the same event and all remember it differently. They are all equally rational in trusting their memories unless evidence comes forward that corroborates one account of the event. However, it can be shown that some properly basic beliefs are not only rational for some people with particular experiences to hold but should be held by all people and anyone who does not hold them to be true is being irrational in doing so, in other words these beliefs are not just beliefs but knowledge.

To understand how a properly basic belief can be a form of knowledge, we must understand Plantinga's distinction ${ }^{33}$ between strong and weak justification and his distinction between prima facie and ultima facie justification, ${ }^{34}$ as well as the role that correctly functioning cognitive faculties have in producing properly basic beliefs when they are working in environments that are appropriate for them. A prima facie justification for a belief is when a proposition that appears true on the surface is accepted as true simply because of

\footnotetext{
${ }^{30}$ Ibid.

${ }^{31}$ Ibid., 44.

${ }^{32}$ Hoitenga, Faith and reason, 155.

${ }^{33}$ Ibid., 191.

${ }^{34}$ Ibid., 190.
} 
this semblance of truth without considering any of the possible reasons for why this belief might be false. An ultima facie or "all things considered" justification is when a proposition is accepted not just because of the surface appearance of truth but because all of the reasons for why this proposition might be false have been considered and discredited. The key difference between a strongly justified belief and a weakly justified belief is the fact that if one has strong justification for a belief, one has an obligation to accept said belief, and if a strongly justified belief is true and there is no apparent possibility of it being false then this belief can be called knowledge. If one only has weak justification for a particular belief, in contrast, one has the right to accept it as true but is under no obligation to do so even if said belief is true. The examples that Plantinga gives of strong and weak justification are a belief justified by testimony (for weak justification) and a belief justified by perception (for strong justification). ${ }^{35}$ Strong justification can also be achieved through sufficient evidence or argument but the form of strong justification that is relevant here is the kind that Plantinga presents in his example of strong justification. A closer look at Plantinga's examples shows precisely what the reasons behind this distinction between weak and strong justification are. The two differ in the fact that a perception is a direct acquaintance with reality, there is no separation between the mind of the perceiver and the object of his belief, whereas in the case of testimony there is a separation between the object of belief and the one that is being testified to, i.e. the witness. This separation results in a belief justified by testimony needing a different set of assumptions to a belief based on perception and creates reasons to doubt a belief based on testimony that does not exist for a belief that is based on perception. I may have a belief about a particular event that is based on the testimony of someone who witnessed it. My assent to this belief requires the assumption that this witness is telling the truth, but, provided nothing is known of the event outside of his testimony and he is not known to be particularly trustworthy or untrustworthy, withholding judgement is a valid position to take. Whether or not one accepts a proposition justified in this way is entirely subjective, a trusting person may accept it and a sceptical person may choose to withhold judgement. This subjectivity is what makes weak justification weak. In this case, what informs a person's decision to accept or reject a proposition justified by testimony might be their natural disposition towards trust or distrust, or it might be their lived experiences, perhaps trusting always had a positive result for them or they were regularly betrayed. It is not irrational for me to decide based on lived experience or disposition whether a justification for some proposition is sufficient for me, provided that said proposition is not actively against reason or evidence, however, someone else may be equally rational in deciding that the same justification is not sufficient for them. Simply put, if a belief is weakly justified it is rational to assent to it for subjective reasons but it is equally rational to refuse to assent to it for subjective reasons. On the other hand, if a belief is strongly justified, assenting to it is rational and refusing to assent to it is irrational. In the example of perception, the lack of separation between the perceiver and the object of his belief means that the reason for doubt that exists in the

35 Ibid., 191-193, "belief on testimony vs belief on appearance." 
first example does not exist here, the information is directly available to the perceiver rather than being relayed through a potentially dishonest witness. The hypothetical possibility that our perceptual faculties may be deceptive is not a reason to doubt beliefs based on perception, since it is in no way grounded in what we know about our perceptual faculties. A correctly functioning brain, paired with correctly functioning senses, has never been known to perceive things that are not there, contrast this with the reason for doubt given in the previous example, which is very much grounded in what we know about people, i.e. that they sometimes lie. As in the previous example, assenting to the belief requires an assumption, namely the assumption that one's perceptual faculties, when functioning correctly, are reliable. Refusing to assent to a belief produced by perception without sufficient evidence that said belief is the result of incorrectly functioning perceptual faculties or of perceptual faculties functioning in an environment to which they are not attuned would mean discarding this assumption, since the only way to justify ones disbelief would be to claim that even correctly functioning perceptual faculties in working in the right environment are unreliable or deceptive. Unlike the assumption in the first example, discarding this assumption would have major epistemic and practical consequences since in doing so one dismisses any possibility of empirical knowledge and can no longer make any decisions based on what one perceives without being inconsistent. If the options are to either make an assumption that is backed up by intuition (our percepts feel real) or to tear down the foundations of empirical knowledge while also making it virtually impossible to live life consistently, the former is clearly the more rational option.

Since it is possible to object to the idea that natural beliefs should be accepted as true by pointing to instances where these faculties were either functioning incorrectly, for example hallucinations, or instances where these faculties were working in an environment they are not attuned to, like someone trying to remember the details of a highly stressful event, it is important to point out that natural beliefs should only be accepted as properly basic if the faculties that produce them are functioning correctly and are working in the right environment when they produce them. Two questions that would probably follow this answer is "what does it mean for a cognitive faculty to function correctly?" and "What does it mean for an environment to be right for some faculty?" It is important that these two questions are answered, in particular since the model of strongly justified belief mentioned above relies so heavily on the idea of correctly functioning cognitive faculties in the right environment. There are two approaches to what it means for a cognitive faculty to function correctly, the first is a theistic approach which claims that each cognitive faculty has a purpose that was assigned to it by God and the faculty functions correctly when it effectively fulfils said purpose, the eye is meant to see real things, the eye is meant to hear real sounds, reason is mean to argue from first principles to a true conclusion. What unites all of these cognitive faculties in this approach is that their ultimate goal is truth and any cognitive faculty that does not produce true beliefs is not functioning correctly. The non-theistic approach claims that the way that these cognitive faculties function is the result of natural selection and their purpose is to maximise an individual's chances of survival and reproduction. Producing 
true beliefs is either necessary for the faculty to fulfil this purpose or is a by-product of a faculty working towards this purpose, the eyes and ears are meant to perceive real things because if they did not the perceiver would be left vulnerable to all kinds of threats, and reason is necessary to construct tools, navigate and perform other tasks which increase one's odds of survival, but the same mental operations necessary for such useful tasks can also be used to reason about the fundamental nature of reality and the meaning of life. For the sake of brevity, I will refer to the former of these approaches as the theistic approach and to the latter as the evolutionary approach. Regardless of which of these approaches one accepts, they both require the belief that a cognitive faculty requires certain physical processes to fulfil its purpose and when these physical processes are somehow altered or removed altogether these faculties will not fulfil their purpose and will therefore function incorrectly. Since both the theistic approach and the evolutionary approach claim that true beliefs are, in one way or another, the result of a cognitive faculties correct functioning, they both accept that incorrect functioning can and does lead to cognitive faculties producing false beliefs. Because of this, any particular natural belief can be refuted, or at least cast into doubt, if it can be shown that the cognitive faculty that produced said belief was functioning incorrectly when producing it. Both of these accounts also acknowledge that our cognitive faculties can only be relied upon to produce true beliefs when they are functioning in the right environments. The theistic account claims that God designed our cognitive faculties to function in particular environments and that when these faculties are working outside of these environments their ability to fulfil their purpose of producing true beliefs is hampered. The evolutionary account claims that, since our cognitive faculties evolved in certain environments, they are attuned to them and are able to reliably produce true beliefs when functioning in them but outside of these environments these faculties lose their ability to carry out their function effectively, in the same way that the fins of a fish, which evolved to function in water, cannot work effectively on dry land. An example of a cognitive faculty outside of its environment would be someone trying to listen in on a conversation in a very noisy place, gathering detailed auditory data is a function of the faculty of hearing but it was never meant to carry out this function in an environment that is flooded with cacophonic noise.

Plantinga's example of a strongly justified properly basic belief provides a blueprint for how a belief can be strongly justified without evidence or argument. Firstly: there must either be no valid reasons to reject the belief, meaning that any arguments presented against the belief must be refuted or the belief is, at best, weakly justified. Secondly: provided that there are no valid reasons to reject the belief, rejecting the belief would require one to abandon some assumption that has epistemic and practical importance comparable to that of the assumption mentioned above.

The fact that beliefs, that are immediately produced by our perceptual faculties, are strongly justified shows that at least one kind of properly basic belief can be called knowledge, provided that it is true, but the idea that perception can be a source of knowledge is nothing new and this is not the case for every natural belief. What reasons there are to 
reject any particular natural belief depends on the belief itself and on what is known about the cognitive faculty that produces it. There are some cognitive faculties that produce strongly justified beliefs, i.e. perception. There are others that produce weakly justified beliefs, one such faculty being intuition since every case of intuition producing a true belief can be countered with a case of it producing a false belief, and there are faculties that produce weakly justified beliefs as well as strongly justified beliefs, an example of this being memory since memory has never been known to be mistaken about the general outline of an event, unless something caused it to function incorrectly, but it has been known to give false information when dealing with small details. Some of the beliefs produced by any one of these faculties may not be justified at all. If some natural belief is found to be illogical or is contradicted by evidence then believing it is clearly irrational. In all of these examples we see some kind of evidence being presented to show that a correctly functioning cognitive faculty in the right environment produces weakly justified beliefs or that a natural belief is entirely unjustified, the reason for this is that one must present a rational argument or evidence from either science or universal human experience to show that any particular natural belief is weakly justified or unjustified. If such evidence does not exist then the default position is that this belief is strongly justified. The reason for this is that when one has an experience that immediately produces a natural belief one has five options: accept the belief as true; present a sound argument or sufficient evidence against this particular belief; present a sound argument against the reliability of this particular faculty; present evidence that in this moment the faculty was functioning incorrectly or in the wrong environment or deny the assumption that our cognitive faculties are reliable, even when functioning correctly and in the right environment. The reason for this is that the assumption that justifies accepting natural beliefs as true is the assumption that the cognitive faculties that produce them are reliable. If no evidence or argument can be found against the belief or against the one specific faculty that produced it, then the only way one can justify not assenting to the belief is by discarding this assumption. It may seem like a stretch to say that rejecting a single belief produced by a single cognitive faculty leads to a blanket rejection of all cognitive faculties, since one could claim that they have no intention of denying the reliability of all cognitive faculties but only deny the reliability of one particular cognitive faculty. Alternatively, they may claim that they do not deny the reliability of the cognitive faculty that produced some natural belief, saying that they only deny the truth of that particular belief. The problem with the first of these responses is that denying the reliability of a single cognitive faculty without a sound argument or sufficient evidence for its unreliability leads to the question of why can the reliability of this specific cognitive faculty be denied without good reason, but the reliability of other cognitive faculties cannot be. To say that we must assume that our cognitive faculties are reliable, but discard that assumption in the case of one specific faculty is a clear case of special pleading. The problem with the second response is that it too is special pleading, if it can be said that the faculty in question has produced a dubious or false belief, and no evidence or argument is needed to support this claim, then why can this not be said 
of other beliefs that this faculty produces. If a cognitive faculty produces dubious or false beliefs then it is unreliable, meaning that this second objection is simply a disguised version of the first.

These first two responses are easily answered and I doubt that many people would respond in this way, but there is a stronger objection that I would like to answer here. One of these objections would be to claim that even though the assumption that our cognitive faculties are reliable is a necessary assumption, there is more to natural beliefs than simply the fact that they are produced by a cognitive faculty. These beliefs are produced immediately and are held in spite of the fact that there is no evidence or argument to support them. Beliefs which are based on arguments or evidence are also produced by a cognitive faculty, namely the faculty of reason but the key difference between them and natural beliefs is the fact that in their case the faculty of reason worked with various pieces of evidence to produce them whereas natural beliefs are produced immediately without any evidence. The person making this objection may then point to various instances where natural beliefs have been found to be false (misremembered events for example) and claim that this provides evidence against the fact that natural beliefs as a whole should be accepted as true until they are disproven, since it is known that they might be false. They shouldinstead not be accepted or rejected until the evidence for and against them has been examined. They may also claim that it is not necessary to assume that our cognitive faculties are reliable regardless of how they produce beliefs since it is possible to assume that we should trust our cognitive faculties to work with evidence in order to form beliefs, but we should not trust a cognitive faculty when it immediately produces a belief for which there is no evidence. The best way to answer this objection would be to show that one cannot believe in the ability of our cognitive faculties to work reliably with evidence without first believing that our cognitive faculties are reliable when they produce natural beliefs and the best way to do that is to go back to the earlier example of perception. As I have already discussed, a belief that is produced when I perceive something, like the belief that I am currently perceiving a table, are natural beliefs, and perception is the method by which evidence is gathered. There is no way to gather the evidence that reason needs to form conclusions without accepting the beliefs that perception produces, immediately and without need for evidence. If each piece of evidence has as its basis a natural belief produced by perception and the claim that natural beliefs should not be accepted as true is believed, then there is no reason to believe that the faculty of reason produces true conclusions by arguing from evidence, not because the faculty of reason itself is unreliable but because there is no reason to believe in the evidence it uses to argue to conclusions. Even if it could be shown that beliefs produced by perception are relevantly different from other natural beliefs and that it is therefore not special pleading to say that such beliefs should be held while other natural beliefs should be rejected, there is still the problem that all beliefs that are produced by the faculty of memory are also natural beliefs; when some memory is recalled the belief that this memory is true is produced immediately as a result of having the memory. Any rational argument that one can make will require that one recall various pieces of evidence that support the 
argument, whether that be an academic study that one has read or something one has seen or any other piece of evidence. Belief in these memories is necessary for the belief that the faculty of reason can reliably argue to true conclusions since an argument that is based on false or dubious evidence cannot be sound. Neither of these points shows that the faculty of reason itself is unreliable, since it is possible for pure reason or mathematical reason to function reliably without needing to rely on memory or perception. There is one more thing to consider, however, which is that the faculty of reason naturally produces belief in its own reliability. When one starts to reason about something, the belief that this reasoning can lead to a true conclusion is present immediately, it does not need to be argued for or supported by evidence and it is produced as a result of the cognitive faculty of reason being engaged. All of this shows that the consequence of denying that the default stance to natural beliefs should be to accept them, is the denial of not only the idea that our cognitive faculties are reliable when they produce natural beliefs, but also of the idea that the faculty of reason is reliable when it reasons to conclusions.

What does all of this mean for the primary concern of reformed epistemology? It means that if there is a sensus divinitatis that immediately produces religious beliefs then some religious beliefs should be accepted as properly basic, what specific beliefs these are depends on what specific account of the sensus divinitatis is accepted. If the attribution account or dispositional account is accurate, then some beliefs that are universal to almost all religions, such as the belief that one or more supernatural agents exist, are properly basic. It could be argued that a version of the attribution account that includes Bering's eToM produces belief in God, although an explanation of how the eToM would produce belief in a morally perfect being is lacking. If the Preparedness account is true, then the case that belief in God is properly basic is far easier to make, since the preparedness account argues for the naturalness of belief in a mind that designed all of nature and is omniscient or at least close to omniscient and, if the findings of Bering and Heywood's study are taken at face value, is compelled to intervene in human lives for moral reasons. However, we do not have evidence to show that belief in the Christian God is natural. Even if it can be shown that the eToM or the cognitive biases described in the preparedness account naturally produce belief in God, it would be an argument for Sikhism or Judaism as much as it would be an argument for Christianity. It could still be used in favour of Christianity, but only as part of a cumulative case. There is one more important thing to point out which is that while beliefs produced by correctly functioning perceptual faculties in the correct environment only need prima facie justification in order to be strongly justified, since there is no rational argument against them and there can be no evidence against them since no reliable evidence can be gathered if one does not assume that such beliefs are true, the belief in God will require ultima facie justification in order to be strongly justified, even if it is properly basic. The reason for this is that there are arguments against the existence of God, such as the argument from evil and the argument from divine hiddenness, which at first glance appear to give a good reason for one to doubt his belief in God. If one is 
aware of these arguments and does not have a sound response to them, then one cannot say that his belief in God is strongly justified.

\section{Conclusion}

In this paper I have shown that there is good reason to believe that some religious beliefs are natural and that natural beliefs are strongly justified provided that there is not sufficient evidence or sound argument against them. Since the field of the cognitive science of religion is still young, more experimental evidence is needed before any one of these accounts could be considered a scientific fact, but this does not mean that there is not a sizeable amount of evidence for the naturalness of some religious beliefs. More importantly, the idea that natural beliefs are properly basic provides an important alternative to the idea that every belief needs to be backed up by evidence or argument and to the common claim that in the debate between theists and atheists the burden of proof is always on the theist. If the cognitive science of religion can show definitively that belief in God is natural and if my arguments here are sound then Plantinga is correct in saying that belief in God is properly basic and we have good reason to reverse this burden of proof. All of this means that reformed epistemology, should it be accepted, would have a major impact not only on how we approach the question of God's existence but also on our understanding of what is a justified belief. I hope that I have shown in this paper that the claims of reformed epistemology have scientific backing and that reformed epistemology ought to be accepted.

\section{Bibliography}

Barrett, Justin L., Rebekah A. Richert, and Amanda Driesenga. "God's beliefs versus mother's: The development of nonhuman agent concepts." Child Development 72, no. 1 (2001): 50-65. DOI: https://doi. org/10.1111/1467-8624.00265

Barrett, Justin L., and Rebekah A. Richert. „Anthropomorphism or preparedness? Exploring children's God concepts." Review of Religious Research (2003): 300-312 DOI: 10.2307/3512389

Bering, Jesse. "Atheism is only skin deep: Geertz and Markússon rely mistakenly on sociodemographic data as meaningful indicators of underlying cognition." Religion 40, no. 3 (2010): 166-168. DOI: 10.1016/j. religion.2009.11.001

Bering, Jesse M. “The existential theory of mind.” Review of General Psychology 6, no. 1 (2002): 3-24.

Clark, Kelly James, and Justin L. Barrett. DOI: 10.1037//1089-2680.6.1.3

Bering, Jesse M., and David F. Bjorklund. "The natural emergence of reasoning about the afterlife as a developmental regularity.” Developmental psychology 40, no. 2 (2004): 217. DOI: 10.1037/0012-1649.40.2.217

Bloom, P. (2005). Descartes' baby: How the science of child development explains what makes us human. Random House.

Pascal Boyer, "the kind of mind it takes" in Religion explained. Random House, 2008. 
Clark, Kelly James, and Justin L. Barrett. "Reformed epistemology and the cognitive science of religion." Faith and Philosophy 27, no. 2 (2010): 174-189 DOI: 10.5840/faithphil201027216

Geertz, Armin W., and Guðmundur Ingi Markússon. "Religion is natural, atheism is not: On why everybody is both right and wrong." Religion 40, no. 3 (2010): 152-165. DOI: https://doi.org/10.1016/j. religion.2009.11.003

Guthrie, Stewart Elliott, and Stewart Guthrie. Faces in the clouds: A new theory of religion. Oxford University Press on Demand, 1995

Heywood, B. T., \& Bering, J. (2010). Do atheists reason implicitly in theistic terms? Evidence of teleofunctional biases in the autobiographical narratives of nonbelievers. Unpublished manuscript, Faculty of Theology and Religion, University of Oxford, Oxford, UK.

Hoitenga, Dewey J. Faith and reason from Plato to Plantinga: An introduction to reformed epistemology. SUNY Press, 1991.

Kelemen, Deborah. "Are children "intuitive theists"? Reasoning about purpose and design in nature." Psychological science 15, no. 5 (2004): 295-301. DOI: https://doi.org/10.1111/j.0956-7976.2004.00672.x

Newman, G., V. Kuhlmeier, F. C. Keil, and K. Wynn. "12-month-olds know that agents defy entropy: Exploring the relationship between order and intentionality." In Poster presented at the Biennial meeting of the Society for Research on Child Development. 2005.

Plantinga, Alvin. "Is belief in God properly basic?” Nous (1981): 41-51. DOI: 10.2307/2215239

Plantinga, Alvin. Warranted christian belief. Oxford University Press on Demand, 2000.

Wellman, Henry M., David Cross, and Julanne Watson. "Meta-analysis of theory-of-mind development: The truth about false belief." Child development 72, no. 3 (2001): 655-684. DOI: https://doi. org/10.1111/1467-8624.00304 